\title{
Friction and wear behaviour of ceramic-hardened steel couples under reciprocating sliding motion
}

\author{
Y.J. He ${ }^{\text {a,* }}$, A.J.A. Winnubst ${ }^{\text {a }}$, D.J. Schipper ${ }^{\text {b }}$, P.M.V. Bakker ${ }^{\text {a }}$, A.J. Burggraaf ${ }^{\text {a }}$, H. Verweij ${ }^{\text {a }}$ \\ a Faculty of Chemical Technology, Laboratory for Inorganic Chemistry, Materials Science and Catalysis, University of Twente, P.O. Box 217, \\ 7500AE, Enschede, Netherlands \\ ${ }^{\mathrm{b}}$ Faculty of Mechanical Engineering, Laboratory of Tribology, University of Twente, P.O. Box 217, 7500AE, Enschede, Netherlands
}

Received 12 May 1994; accepted 29 September 1994

\begin{abstract}
The friction and wear bchaviour of $\mathrm{ZrO}_{2}-\mathrm{Y}_{2} \mathrm{O}_{3}, \mathrm{ZrO}_{2}-\mathrm{Y}_{2} \mathrm{O}_{3}-\mathrm{CeO}_{2}$ and $\mathrm{ZrO}_{2}-\mathrm{Al}_{2} \mathrm{O}_{3}$ composite ceramics against hardened steel AISI-52100 were investigated using a pin on plate configuration under reciprocating motion. The reproducibility of the results was examined in this configuration. Wear characteristics were separated into system and material contributions. Under the conditions used, all the ceramic components exhibited rather low wear rates (less than $10^{-6} \mathrm{~mm}^{3} \mathrm{~N}^{-1} \mathrm{~m}^{-1}$ ). The frictional behaviour of ceramic-metal couples depended on a metallic layer transferred from the steel plate to the ceramic pin. A relation was determined between surface hardness and friction of ceramic-metal pairs. It was shown that the affinity for the transfer of the metal towards ceramic surfaces depended on the physical properties of the materials. In the tribosystems investigated, the effect of the hardness of the ceramics on friction and wear behaviour is found to be more important than that of toughness of the ceramics.
\end{abstract}

Keywords: Ceramics; Sliding; Friction; Wear; Adhesion

\section{Introduction}

Fine structured ceramics are being developed for a wide variety of engineering applications including metal cutting tool inserts, drawing dies, roller bearings, water pumps, automotive engine parts. In all these cases, excellent tribological characteristics are required [1]. Many studies are performed on the friction and wear behaviour and chemical interactions of metal-ceramic couples in sliding contacts with non-oxide ceramics such as silicon nitride, silicon carbide, etc. These non-oxides, however, demonstrate poor chemical stability in air at high temperature and even suffer from oxidation under tribological sliding conditions [2]. Considerable attention has been paid to the development of toughened zirconia and toughened alumina ceramics in the past few years owing to their good mechanical properties and chemical resistance.

Transformation-toughened $\mathrm{ZrO}_{2}$ has widened the scope of application of oxide ceramics owing to its excellent fracture toughness. The primary mechanism of toughening in $\mathrm{ZrO}_{2}$ ceramics with grain sizes surpassing a critical value is the transformation of a retained metastable tetragonal phase to a stable monoclinic phase in the vicinity of propagating cracks.

\footnotetext{
* Corresponding author.
}

The volume dilation accompanying the transformation produces compressive zones which retard crack propagation [3]. The tetragonal phase of zirconia can be retained by addition of a certain amount of rare earths oxides as yttria, ceria or both. Zirconia-toughened alumina (ZTA) with improved toughness has been developed by the introduction of the metastable tetragonal zirconia phase in an alumina matrix [4,5]. Narutaki et al. [6] have reported that ZTA exhibits superior resistance to crater wear in face milling, which can be attributed possibly by reversible tetragonal to monoclinic transformation of $\mathrm{ZrO}_{2}$ during milling wear. Sornakumar et al. [7] also expected that this cyclic transformation can result in a better surface texture and reduce surface roughness in alumina-zirconia composite cutting tools. However, the occurrence of microcracks on the surface owing to stressinduced transformation [8] may reduce the wear resistance of ZTA.

It has been reported that some ceramic-metal pairs have lower coefficients of friction than ceramic-ceramic sliding contacts [9]. Experiments have demonstrated that the wear mechanisms of some metals when rubbed against ceramics under dry conditions are governed by a transfer of metal to the ceramic surface $[9,10]$. It is found that wear and friction of metals against ceramics strongly depends on the chemical 
reactivity of the metal [11]. For effective application of these materials more detailed research of the interaction of the ceramic-metal couples and the dominant wear mechanism are very important.

In this paper, friction and wear behaviour between zirconia matrix ceramics and hardened steel AISI-52100 are investigated under reciprocating sliding conditions. The experiments were carried out using ceramic pins which were loaded and slid against hardened steel plates under different conditions, such as unlubricated sliding motion in air and sliding motion in distilled water. The transferred metal layers on the wear scar surface of the ceramics were characterized by a microindenter and a scanning clectron microscope (SEM) with energy-dispersive X-ray (EDX) system. The wear track morphology was determined by SEM as well.

\section{Experimental procedure}

\subsection{Materials for testing}

In the present study three kinds of ceramic materials and one type of steel were used. Ultra fine tetragonal zirconia powders ZY5 (zirconia doped with $5 \mathrm{~mol} \% \mathrm{YO}_{1.5}$ ), ZY4Ce4 (zirconia doped with $4 \mathrm{~mol} \% \mathrm{YO}_{1 / 2}$ and $4 \mathrm{~mol} \% \mathrm{CeO}_{2}$ ) and a ZTA composite ( 85 wt. $\% \mathrm{Al}_{2} \mathrm{O}_{3}-15$ wt. $\% \mathrm{ZrO}_{2}$ ) powder were synthesized by a gel precipitation technique as described in detail by Groot Zevert et al. [12]. All the ceramic compacts were prepared by cold isostatic pressing at $400 \mathrm{MPa}$. After that $\mathrm{ZY5}$ and $7 \mathrm{YY} 4 \mathrm{Ce} 4$ samples were sintered at $1150^{\circ} \mathrm{C}$ for $10 \mathrm{~h}$. A grain size of $0.18 \mu \mathrm{m}$ was obtained in both $\mathrm{ZrO}_{2}$ materials. While ZTA was sintered at $1450{ }^{\circ} \mathrm{C}$ for $2 \mathrm{~h}$ and had an $\mathrm{Al}_{2} \mathrm{O}_{3}$ grain size of $0.8 \mu \mathrm{m}$ and a $\mathrm{ZrO}_{2}$ grain size of $0.3 \mu \mathrm{m}$. Grain sizes $D$ were determined by the linear intercept technique from SEM micrographs of a polished and thermally etched surface, using $D=1.56 L$, where $L$ is the average linear intercept [13]. The ceramic specimens, formed into cylinders with $5 \mathrm{~mm}$ diameter and $10 \mathrm{~mm}$ length, slid reciprocally against hardened bearing steel (AISI-52100). The roughness $R_{\mathrm{a}}$ along the axis direction of the TZP cylinders is $0.5 \mu \mathrm{m}$ and $R_{\mathrm{a}}$ of ZTA is $0.2 \mu \mathrm{m}$. The stationary steel plate with dimensions of $56 \mathrm{~mm} \times 18 \mathrm{~mm} \times 5 \mathrm{~mm}$, had a mean surface roughness $R_{\mathrm{a}}$ of $0.5 \mu \mathrm{m}$. Before testing, all samples were cleaned ultrasonically with ethyl alcohol. Subsequently the samples were annealed for $10 \mathrm{~min}$ at $950{ }^{\circ} \mathrm{C}$ for $\mathrm{ZY} 5$ and ZY4Ce 4 and $1350{ }^{\circ} \mathrm{C}$ for ZTA in order to remove residual stresses caused by machining. Physical and mechanical properties of ZY5, ZY4Ce4 and ZTA ceramics and AISI-52100 hardened steel are listed in Table 1. All properties of AISI52100 hardened steel were quoted from a metals handbook [15]. The densities of the sintered ceramics were measured by the Archimedes technique in mercury. The bending strength and the fracture toughness were measured by 4 point bending and single edge notched beam, respectively, as described in [5]. The Vickers hardness of ceramics were measured using a microindenter (Shimadzu Dynamic Ultra Hardness Tester DUH-200) with a maximum load of $2 \mathrm{~N}$ and a loading speed of $1.44 \times 10^{-3} \mathrm{~kg} \mathrm{~s}^{-1}$. A hold time was used of $10 \mathrm{~s}$. The Young's modulus is calculated using the unloading vs. indentation depth curve after loading test [16]. The dynamic hardness of the ceramics and the steel, as obtained from load and indentation depth [17], is measured using the same microindenter with the loads from 0.2 to $50 \mathrm{gf}$.

\subsection{Test equipment}

Friction and wear tests were performed on a pin on plate type sliding wear tribometer (code: S-tribometer). This Stribometer, as shown schematically in Fig. 1(a), consists of a reciprocating pin sliding on a stationary plate with its axis

Table 1

Mechanical and physical properties of the ceramic and the metallic materials

\begin{tabular}{|c|c|c|c|c|}
\hline Material & ZY5 & $\mathrm{ZY} 4 \mathrm{Ce} 4$ & ZTA & AISI-52100 hardened steel \\
\hline Chemical composition & $\begin{array}{l}95 \mathrm{~mol} \% \mathrm{ZrO}_{2}, 5 \mathrm{~mol} . \% \\
\mathrm{Y}_{2} \mathrm{O}_{3}\end{array}$ & $\begin{array}{l}92 \mathrm{~mol} . \% \mathrm{ZrO}_{2}, 4 \mathrm{~mol} . \% \\
\mathrm{Y}_{2} \mathrm{O}_{3}, 4 \mathrm{~mol} . \% \mathrm{CeO}_{2}\end{array}$ & $\begin{array}{l}85 \mathrm{wt} . \% \mathrm{Al}_{2} \mathrm{O}_{3}, 15 \mathrm{wt} . \% \\
\mathrm{ZrO}_{2}\end{array}$ & $\begin{array}{l}1.1 \% \mathrm{C}, 0.40 \% \mathrm{Mn}, 0.1 \% \\
\mathrm{Ni}, 0.30 \% \mathrm{Si}, 1.5 \% \mathrm{Cr} \\
0.01 \% \mathrm{~V}, 0.005 \% \mathrm{Mo} \\
\text { residual } \mathrm{Fe} \text { (wt. } \% \text { ) }\end{array}$ \\
\hline Density $\left(\times 10^{3} \mathrm{~kg} \mathrm{~m}^{-3}\right)$ & 5.8 & 5.9 & 4.1 & 7.9 \\
\hline Vickers hardness (GPa) & 13.0 & 12.2 & 17.0 & 7.6 \\
\hline Dynamic hardness (GPa) & 8.1 & 7.6 & 10.2 & 6.3 \\
\hline $\begin{array}{l}\text { Fracture toughness }\left(\mathrm{MPa} \mathrm{m} \mathrm{m}^{1 / 2}\right) \\
\text { at } T_{\text {room }}\end{array}$ & 8.6 & 6.5 & 5.2 & 20 \\
\hline Young's modulus (GPa) & 191 & 173 & 262 & 213 \\
\hline Poisson's ratio & 0.30 & 0.30 & 0.30 & 0.29 \\
\hline Strength $^{\mathrm{a}}(\mathrm{MPa})$ & 454 & 430 & 380 & 345 \\
\hline $\begin{array}{l}\text { Coefficient of thermal } \\
\text { expansion }\left(\mu \mathrm{m} \mathrm{m} \mathrm{m}^{-1} \mathrm{~K}^{-1}\right)\end{array}$ & $9.3^{b}\left(20-400^{\circ} \mathrm{C}\right)$ & $9.3^{\mathrm{b}}\left(20-400^{\circ} \mathrm{C}\right)$ & $7.5^{\circ}\left(20-400^{\circ} \mathrm{C}\right)$ & $12.6\left(20-100^{\circ} \mathrm{C}\right)$ \\
\hline $\begin{array}{l}\text { Thermal conductivity } \\
\qquad\left(\mathrm{W} \mathrm{m}^{-1} \mathrm{~K}^{-1}\right)\end{array}$ & $2.5^{\text {b }}\left(\right.$ at $150^{\circ} \mathrm{C}$ ) & $2.5^{\mathrm{b}}$ (at $150^{\circ} \mathrm{C}$ ) & $5.5^{\circ}\left(\right.$ at $\left.150^{\circ} \mathrm{C}\right)$ & $45.0\left(\right.$ at $\left.100^{\circ} \mathrm{C}\right)$ \\
\hline
\end{tabular}

${ }^{a}$ Four-point bending strength for the ceramics; yield strength for the steel.

${ }^{b}$ Data from ref. [14]. 


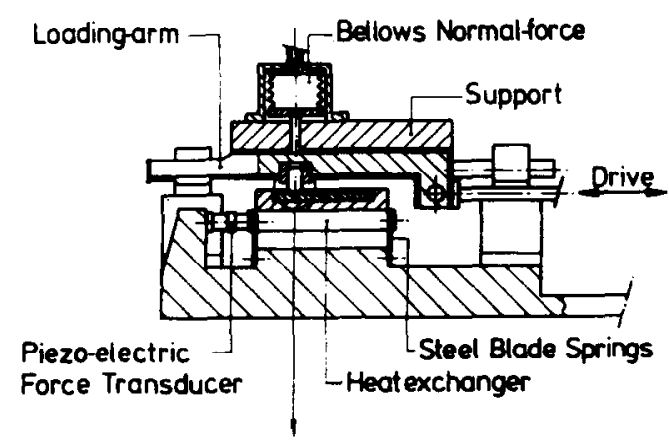

(a)

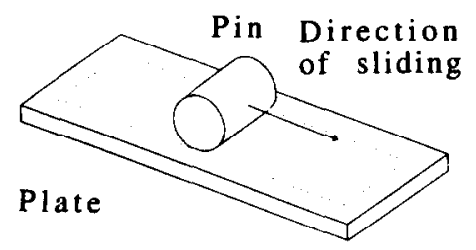

(b)

Fig. 1. (a) S-tribometer. (b) . Contact situation of the pin on the plate.

parallel to the steel plate. The plate is fixed by a holder, which is mounted on a heat exchanger, which in turn are supported by two steel blade springs which only allow parallel movement in the sliding direction. The pin is fixed in a loading arm, which is connected to the support. The support, guided by two cylindrical bars that are supported by a system of 4 roll-blocks, is driven by a crank mechanism. The pin, therefore, exerts a sinusoidal motion with an amplitude $A=23$ $\mathrm{mm}$. The pin is loaded by pressurizing the bellows, in which the pressure is kept constant by connecting it to an air-accumulator. The bellows pressure is measured by a manometer. The friction force, induced between cylindrical pin and plate, is measured by a piezoelectric force transducer and recorded, using a digital oscilloscope. In Fig. 1(b) the contact situation is schematically shown. The initial contact between the pin specimen and the plate specimen is a linear contact.

\subsection{Test procedure and characteristics}

The experiments were carried out under dry sliding conditions at room temperature of $22-24{ }^{\circ} \mathrm{C}$ with a relative humidity of about $50 \%$ and under lubricated conditions in distilled water. All experiments are performed at a frequency of $0.22 \mathrm{~Hz}$ with a mean velocity of $20 \mathrm{~mm} \mathrm{~s}^{-1}$ and a normal load varying from 65 to $200 \mathrm{~N}$, corresponding to an average value of the initial hertzian contact pressure of unworn surfaces from 170 to $320 \mathrm{MPa}$, respectively, which is calculated by a formula given in ref. [18]. The wear experiments from which friction and wear are obtained as a function of sliding distance are performed at a mean sliding velocity of $20 \mathrm{~mm}$ $\mathrm{s}^{-1}$ and a load of $65 \mathrm{~N}$. The volume loss is calculated from the weight loss and the density of the coupled elements. The specific wear rate $k_{\text {inst }}$, at a given stage of the process, is calculated from the equation as given below: $k_{\text {inst }}=\frac{1}{F_{\mathrm{n}}} \frac{\mathrm{d} V}{\mathrm{~d} S}$

in which $V$ is the volume loss and $S$ the sliding distance at a normal force $F_{\mathrm{n}}$. Thus, $k$ is proportional to the slope of the volume loss vs. sliding distance curves.

The values of the coefficient of friction are calculated from the normal load and the friction force obtained from a digital oscilloscope.

After the tests, the wear scars of the ceramic cylinders and the wear debris were cxamined using a scanning clectron microscope (SEM) (Jeol JSM-35CF) equipped with an energy-dispersive X-ray (EDX) analyzer or an SEM (Hitachi S800) with an ultra-thin-window EDX (for light element analysis down to boron) analyzer to determine the surface degradation process and the dominant wear mechanisms. The phase composition was analyzed by $\mathrm{X}$-ray diffraction (XRD) using a Phillips PW1370 diffractometer with $\mathrm{Cu} \mathrm{K} \alpha$ radiation. The characteristics of the wear debris and adhesive layer were examined by XRD analysis and ultra-thin-window EDX.

After sliding tests the dynamic microhardness of the worn surfaces or the metallic layer which was transferred from the steel to the ceramic surface was determined by the microindenter as described in Section 2.1 above. In this case, classical microhardness could not be measured because the metallic layer was only a few microns thickness. As a consequence, the dynamic hardness was used in this study. The surface roughness of the samples was measured with a Dek-Tak profilometer.

\section{Experimental results}

\subsection{Reproducibility of tribological results}

Figs. 2 and 3 show the friction and wear results of ZY5 and $\mathrm{ZY} 4 \mathrm{Ce} 4$ ceramics after duplex testing under the same

\section{Ceramic against metal S-tribometer (dry-sliding)}

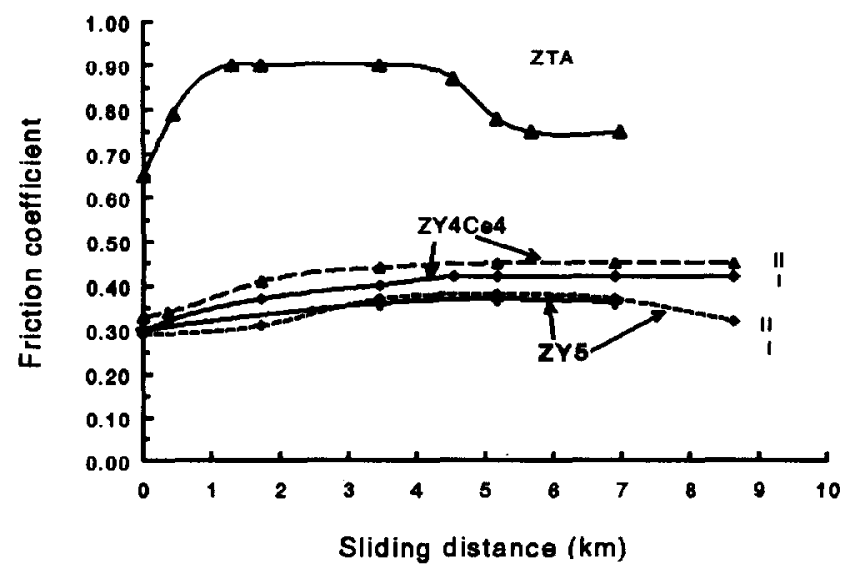

Fig. 2. Coefficient of friction vs. sliding distance for different tribological couple combinations. I (dotted line) and II (solid line) reveal the results of two tests performed at the same conditions. 


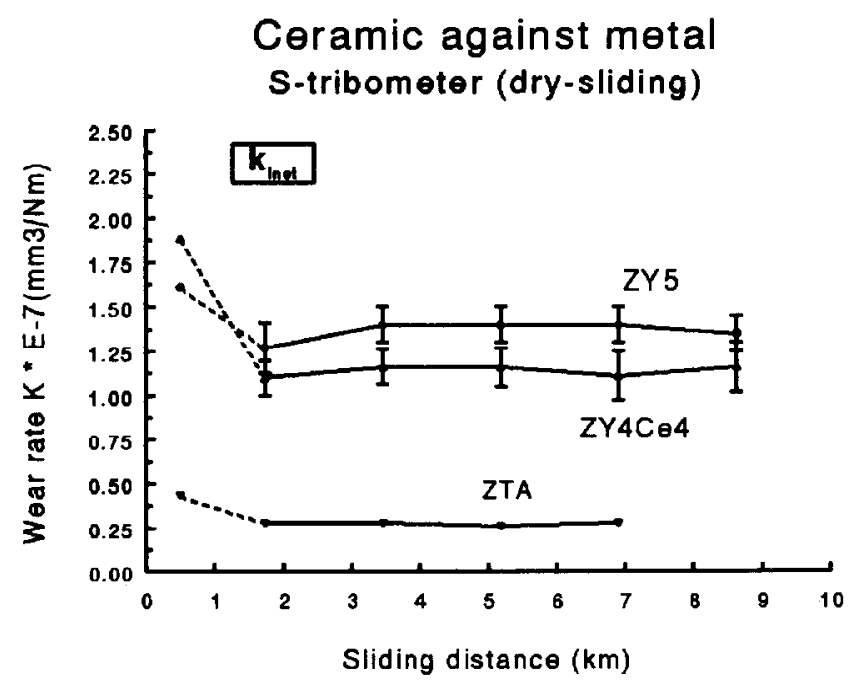

Fig. 3. Wear rate of the ceramics vs. sliding distance for different ceramicmetal couples.

testing conditions. It is clear from these figures that the results obtained show a very good reproducibility. This reproducibility is of an importance in specifications of the quality of the materials used and is an indication of the reliability of the tests. For a tribosystem the reproducibility depends on two aspects:

(1) The material itself must have a homogeneous and reproducible microstructure, and surface properties of the coupled elements like roughness and microhardness must remain the same.

(2) During friction and wear testing, constant environmental conditions such as temperature, chemical nature and relative humidity are necessary. The cylinder pin must be in line with the plate in its axis direction. A decrease of contact line or area, due to misalignment, will increase the contact pressure (the loading force is constant), which may result in different values for wear and coefficient of friction.

From the results it can be concluded that the ceramic materials used and the results obtained from the tribosystems used in this investigation are useful data.

\subsection{Influence of different ceramic components on friction}

Representative friction registration curves for all three experimental ZY5-, ZY4Ce4- and ZTA-AISI-52100 speciInen pairs are plotted in Fig. 2 as a function of the sliding distance. The frictional behaviour of material pairs with different ceramic components is significantly different. A large change in the value of the coefficient of friction $\mu$ with increasing sliding distance was found for the ZTA-AISI52100 couple during the running-in period. In this couple as can be seen from Fig. 2 the initial value of the coefficient of friction was 0.65 , then increased with sliding distance to a value of about 0.9 remaining steady for approximately $4 \mathrm{~km}$. After $4.5 \mathrm{~km}$ the friction coefficient decreases to another steady value of about 0.75 .
In contrast, for ZY5- and ZY4Ce4-AISI-52100 steel couples, a coefficient of friction $\mu$ of $0.3-0.4$ is measurcd, which remained almost constant during the test. The values of the coefficient of friction show a smaller variation during the running-in period if compared with the ZTA-AISI-52100 couple. The different values in coefficient of friction between ZTA and TZP (ZY4Ce4 and ZY5) are suggested to be related to the adhered film on ceramics, which will be discussed later. The test with ZTA was also associated with the highest noise level. In the case of ZY5- and ZY4Ce4-metal couples, noise was hardly generated during sliding.

\subsection{Wear rate of the tribological components}

Ceramic wear rate vs. sliding distance is shown in Fig. 3. The TZP samples show a decrease in wear rate when the sliding distance increases (dotted line in Fig. 3) which is due to the running-in for ZY5 and ZY4Ce4 ceramics at the beginning of wear process. The wear subsequently reached a steady state after a sliding distance of approximately $1 \mathrm{~km}$.

As shown in Fig. 3, the wear rate of ZTA ceramic is a factor of 3 to 4 lower than for ZY5 and ZY4Ce4. The wear rate values for ceramics and steel after about $6.8 \mathrm{~km}$ of sliding distance are summarized in Fig. 4. For the ZTA-AISI-52100 couple the steel plate had a significantly higher wear, i.e. $83 \times 10^{-6} \mathrm{~mm}^{3} \mathrm{~N}^{-1} \mathrm{~m}^{-1}$. While for the tests with ZY5 and $\mathrm{ZY} 4 \mathrm{Ce} 4$, the wear rates of the metallic plates were $1.6 \pm 0.3 \times 10^{-6} \mathrm{~mm}^{3} \mathrm{~N}^{-1} \mathrm{~m}^{-1}$ and $0.4 \pm 0.1 \times 10^{-6} \mathrm{~mm}^{3}$ $\mathrm{N}^{-1} \mathrm{~m}^{-1}$, respectively.

Comparison of the results of both TZP-AISI-52100 couples indicates that there is a slight difference in the specific wear rates between $\mathrm{ZY} 5$ and $\mathrm{ZY} 4 \mathrm{Ce} 4$ ceramics, whereas the wear rate of the AISI-52100 metal in combination with ZY5 as mentioned before is approximately a factor of 4 higher than in the ZY4Ce4-metal couple.

After the tests, it was found that the ceramic wear scars were black, dark red or brown, indicating that metal particles

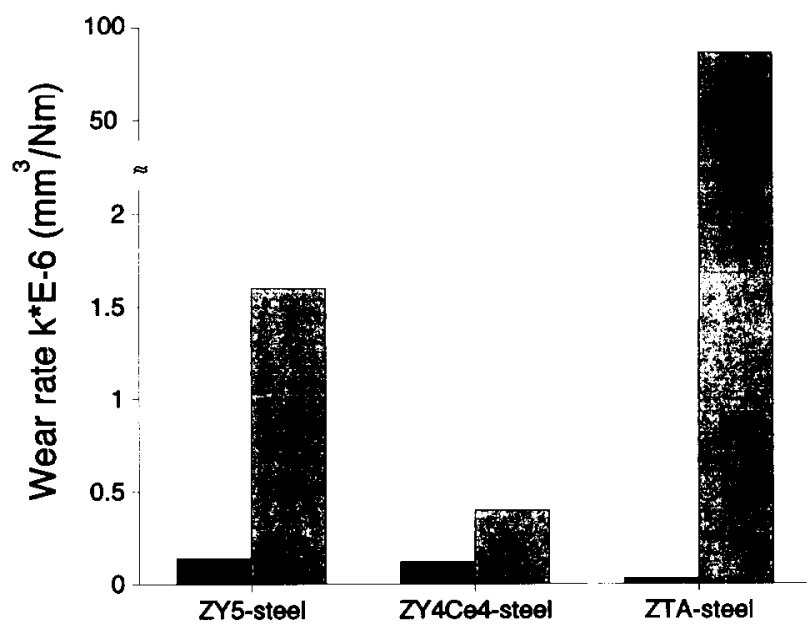

Fig. 4. The ranking order for the specific wear rate values of the tribosystem and the individual material components after a sliding distance $6.8 \mathrm{~km}$. 


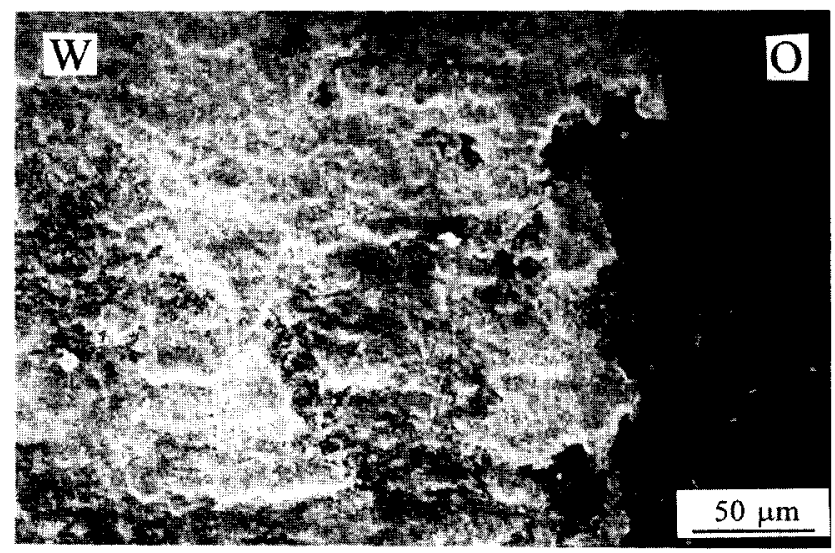

(a)

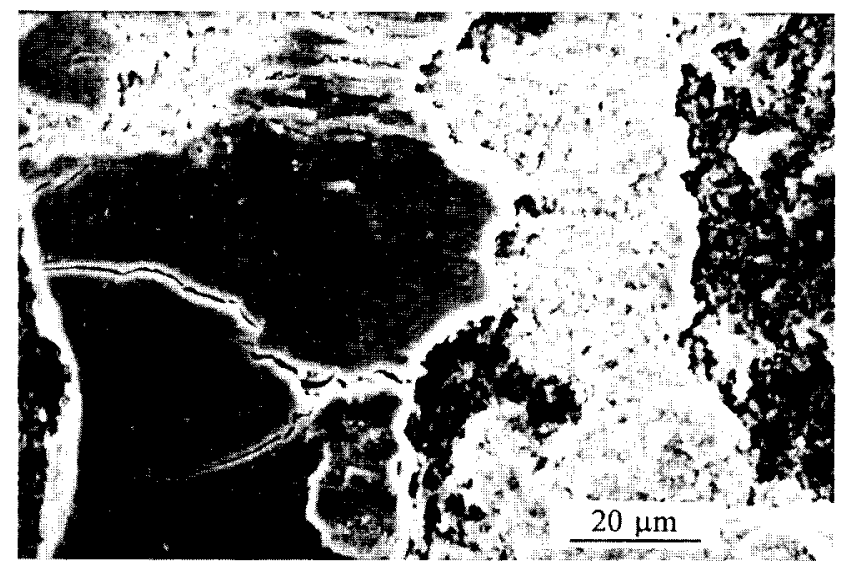

(b)

Fig. 5. SEM of wear tracks of ZTA surface after the dry tribological test at a sliding speed of $20 \mathrm{~mm} / \mathrm{s}$ and a normal load of $65 \mathrm{~N}$. (a) Overview of the wear track: the thick metallic layer on the surface. (b) High magnification detail of the layer. $O$, Original surface; $W$, wear track. The arrow indicates the sliding direction.

or metal oxides were transferred to the ceramic cylinder surface in all cases.

Wear tracks of the ceramics after sliding are shown in Fig. 5 and Fig. 6. Much more metal is transferred from the AISI52100 plate to the surface of ZTA as shown in Fig. 5(a) if compared with TZP (Fig. 6). The wear track revealed a continuous and thick metallic film adhered on the ZTA surface. Examination of a polished cross-section of the wear scar of the ZTA pin by SEM indicated that the thickness of the layer is about $3 \mu \mathrm{m}$. Many flat and thick areas were found together with rough areas. These rough areas are due to the delamination of the thick layer and the loss of particles from the metallic layer (see Fig. 5(b)). Ultra-thin-window EDX used for analyzing the metallic layer indicates the existence of iron oxides qualitatively. In the thick layer adhered on the ZTA surface the signal of the aluminum element is hardly found by this method. These results also confirm the presence of the metallic layer on the ceramic surface.

The wear surface of ZY5 is smooth and some grooves in the sliding direction are visible as shown in Fig. 6(a). The amount of metallic material deposited on ZY5 surface is very small as analyzed by EDX. Only a few thicker traces (black parts) in a small scale adhered to the surface are observed (Fig. 6(a)). In most cases, however, the presence of metallic particles attached to the surface can be identified only by the brown colour on the worn surface using optical microscopy. In addition, some microfracture of the ceramic surfaces took place within the limits of area. Very smooth wear tracks are observed in ZY4Ce4 ceramics (Fig. 6(b)). A very thin metallic film is adhered to the ceramic surface. Only limited relative thick metallic films can be found on the surface as was also observed for ZY5.

The wear debris was collected after testing. For ZTAAISI-52100 the wear debris is black or dark red, whercas for TZP-AISI-52100 the wear debris was brown. The change in colour from black to brown would be in correspondence with an increase in contact temperature during wear test processes as suggested by Stachowiak et al. [10]. Also a correlation exists between the colour of the debris and the relative amounts of ceramic wear and metal wear as indicated by Libsch et al. [19]. If ceramic wear is the same or higher

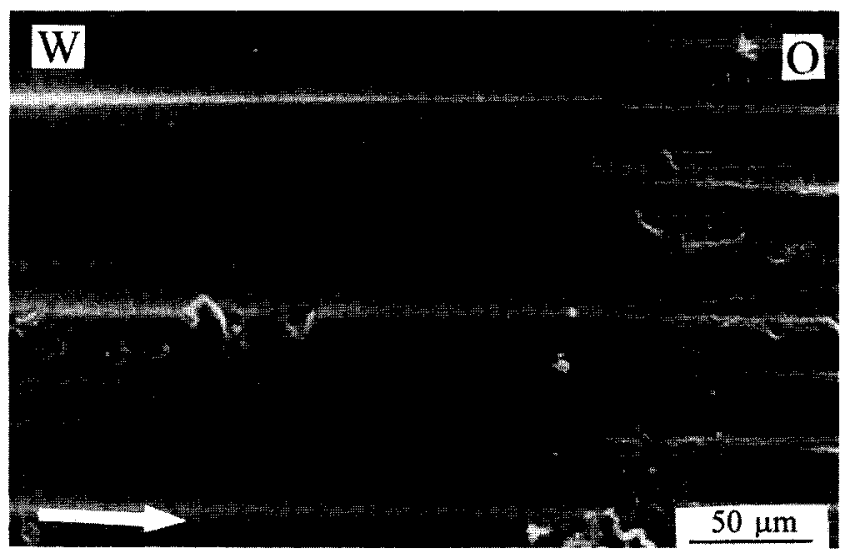

(a)

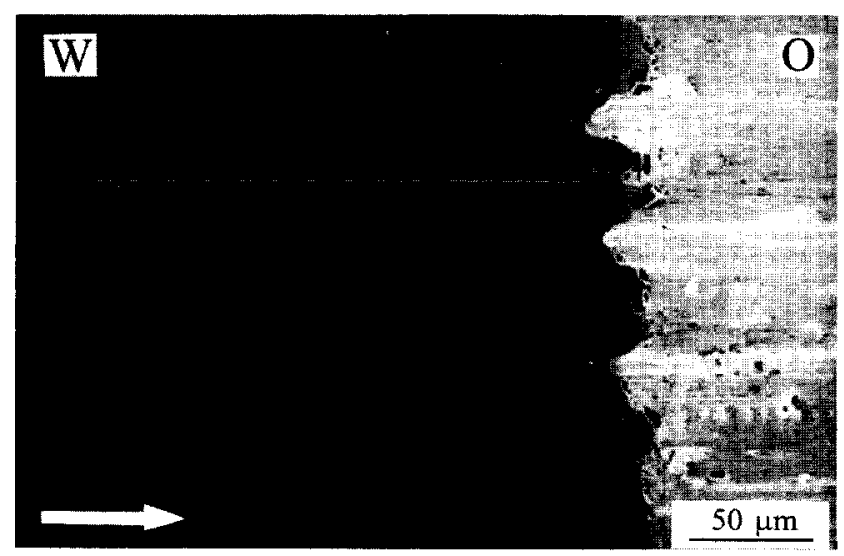

(b)

Fig. 6. SEM of wear tracks of TZP surface after the dry tribological test at a sliding speed of $20 \mathrm{~mm} / \mathrm{s}$ and a normal load of $65 \mathrm{~N}$. (a) Wear track of ZY5 surface: microfracture on small scale, very small amount of metallic particles as islands attached to the surface, grooves in the sliding direction and microfracture in small areas. (b) Wear track of ZY4Ce4 surface. $\mathrm{O}$, original surface; $\mathrm{W}$, wear track. The arrow indicates the sliding direction. 
Table 2

Characteristics of the ZTA-AISI-52100 couple after $3.4 \mathrm{~km}$ sliding wear

\begin{tabular}{rll}
\hline $\begin{array}{l}\text { Load } \\
(\mathrm{N})\end{array}$ & $\begin{array}{l}\text { Coefficient of } \\
\text { friction }\end{array}$ & $\begin{array}{l}\text { Specific ceramic wear rate } \\
\left(\mathrm{mm}^{3} \mathrm{~N}^{-1} \mathrm{~m}^{-1}\right)\end{array}$ \\
\hline 65 & 0.9 & $0.33 \pm 0.02 \times 10^{-7}$ \\
130 & 0.8 & $0.19 \pm 0.02 \times 10^{-7}$ \\
200 & 0.8 & $0.51 \pm 0.10 \times 10^{-7}$ \\
\hline
\end{tabular}

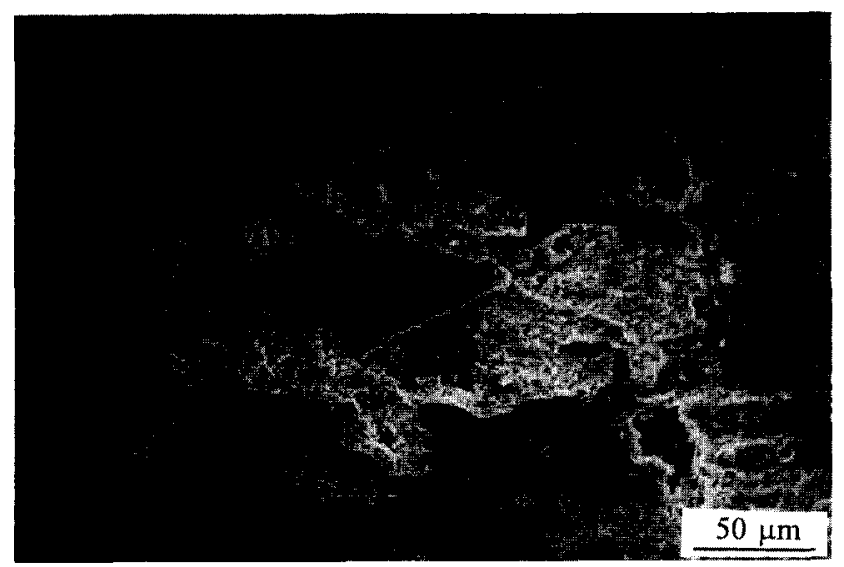

(a)

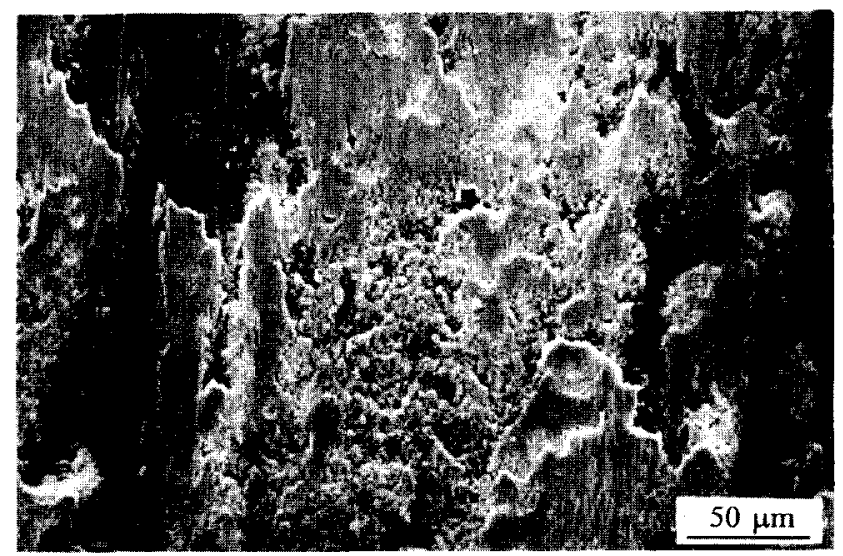

(b)

Fig. 7. SEM of the wear surfaces of ZTA. (a) Sliding wear test at normal load of 65 N. (b) Sliding wear test at normal load of 200 N. The arrow indicates the sliding direction.

relative to metal wear, then the wear debris colour is light. If ceramic wear is less than metal wear, then the wear debris colour is dark [19]. This explanation was based on the fact that the wear debris was a mixture of dark iron oxide from the metal and light coloured ceramic powder. Thus the wear debris produced in ZTA-AISI-52100 couple contains less amount of the ceramic powder than in TZP-AISI-52100, which is in agreement with the results of wear rates where ZTA ceramics show much less wear loss than TZP ceramics. The XRD pattern of the wear debris indicates that the wear debris contains iron oxide products $\left(\mathrm{Fe}_{2} \mathrm{O}_{3}\right.$ and $\left.\mathrm{Fe}_{3} \mathrm{O}_{4}\right)$, metallic and ceramic turnings. The presence of the iron oxides confirms that a tribochemical reaction exists. The presence of iron oxide also indicates that the accumulation of heat during dry sliding is sufficient to oxidize the fine crushed dcbris. This accumulation of heat is due to the low thermal conductivity of the ceramic materials. Numerous studies have reported a tribochemical interaction during sliding tests of ceramics against metal under dry conditions $[10,19-23]$. Ravikiran et al. [23] also found the existence of $\mathrm{FeAl}_{2} \mathrm{O}_{3}$ and $\mathrm{FeAlO}_{3}$ besides iron oxides during dry sliding of alumina pins against a steel disc (En24). However, these spinel products were not detected for the ZTA-AISI-52100 couple in the present study.

\subsection{Effect of loading force on tribological properties}

The effect of loading force in the range of 65 to $200 \mathrm{~N}$ on the tribological behaviour was examined for the ZTA-AISI52100 steel pair combination. The friction and wear values for the ceramic part are listed in Table 2.

The friction coefficient values appeared to be nearly independent of load in agreement with the observations of [10]. The variation in the wear rate of ZTA ceramic indicates that the effect of load on the wear loss is not very straightforward. However, increasing the load is associated with a rapid increase of metal wear, resulting in the accumulation of metal debris at the borders of the wear track. The morphology of the metallic film on the ceramic is examined by SEM as shown in Fig. 7. Comparison of the wear tracks between sliding at $65 \mathrm{~N}$ (see Fig. 7(a)) and $200 \mathrm{~N}$ (see Fig. 7(b)) normal loads reveals that the only difference at high load is that the metallic film becomes more flat and that its continuity is decreased, e.g. more original ceramic contact surface is exposed (Fig. 7(b)). But no more changes in the metallic film are observed for all loads. It can be concluded that there is no difference of the friction and wear values as function of load in the ZTA-metal system.

\subsection{Wear behaviour of ZY4Ce4 ceramic against metal in water}

Fig. 8 and Fig. 9 show the coefficient of friction and wear loss for the ZY4Ce4-AISI-52100 couple during sliding in air

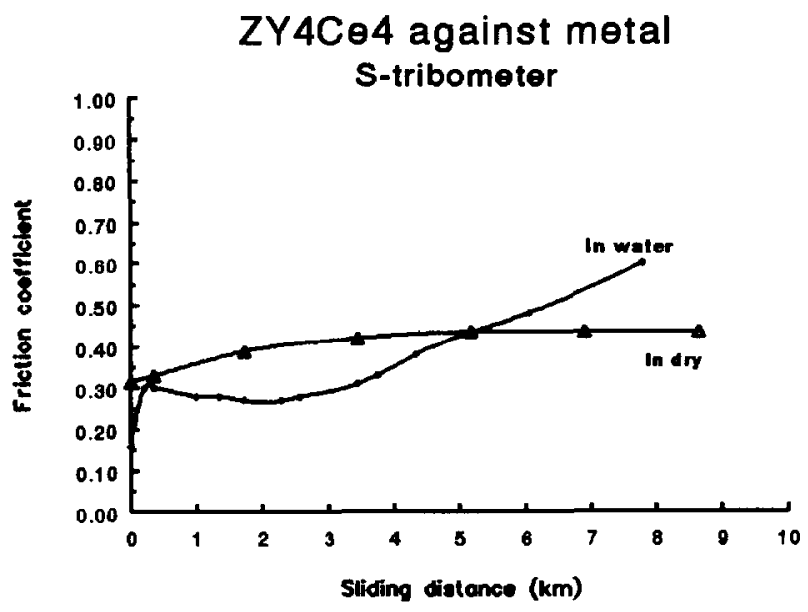

Fig. 8. Friction coefficient as a function of sliding distance for $\mathrm{ZY} 4 \mathrm{Ce} 4$ under dry sliding and lubricated (water) conditions. 


\section{Ceramic against metal S-tribometer (in water)}

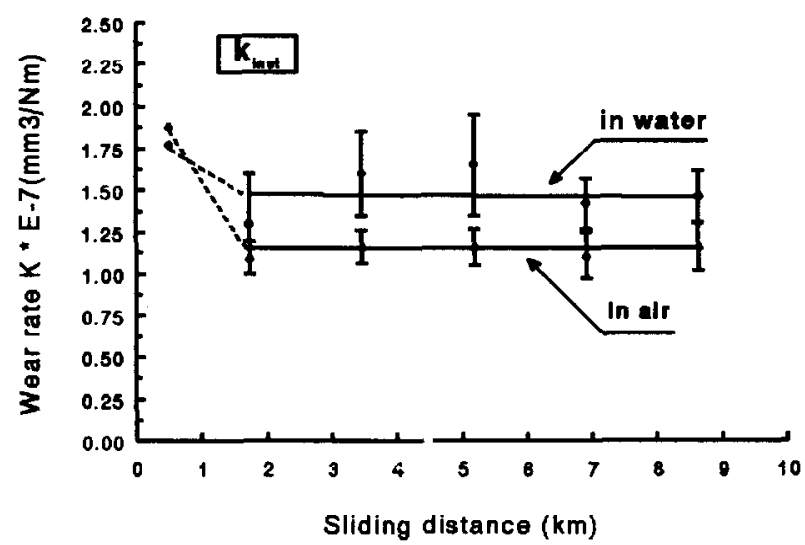

Fig. 9. Wear rates for $\mathrm{ZY} 4 \mathrm{Ce} 4$ as a function of sliding distance under dry sliding and lubricated (water) conditions.

and in water, respectively. At the beginning, water acts as a lubricant and reduces the friction force, resulting in a lower friction coefficient. After a certain sliding distance, the coefficient of friction increases, which probably corresponded to the formation of iron oxide products owing to the strong metal oxidation observed during the sliding test. It can be seen from Fig. 9 that the wear loss in water is larger than that in air. This result corresponds to the fact that water promotes wear owing to tribochemical reaction between water and zirconia which will be discussed later. The wear loss of the metal plate cannot be measured because of oxidation.

\section{Discussion}

\subsection{Amount of metal adhered on the ceramic surface}

For discussion concerning friction and wear it is important to take the influence of the transferred films into account. A difference in metal adherence on the various ceramics is observed, i.e. the metallic layer attachment to ZTA ceramic (see Fig. 5) is much more stronger than to $\mathrm{ZY} 5$ and ZY4Ce4 (see Fig. 6). The transferred metallic layer prevents direct contact between metal and ceramic, and therefore controls the friction and wear behaviour of the sliding couples. This is in agreement with the results for tribological tests with metal-ceramic couples in Refs. [10,20-22]. For ZTA-AISI52100 couple, an increase in the coefficient of friction is an indication of the onset of the deposition of a metallic film on the ceramic surfaces [10].

In contrast, much less transferred metallic particles are detected with TZP ceramics. It is well known that generally, metallic films attach well to ceramic contact faces because of a strong interfacial adhesion between the sliding surfaces. The difference in the ability of metal attachment to the ceramic surface between ZTA and TZP is probably related to the difference of interfacial energy between the ceramics and the metal.
Howe [24] introduced the use of the work of adhesion $W_{\text {ad }}$ which is the work requircd to separatc a unit area of interface into the two original surfaces. $W_{\text {ad }}$ can be separated into $W_{\mathrm{ad}}=\gamma_{\mathrm{m}}+\gamma_{\mathrm{c}}-\gamma_{\mathrm{mc}}$, where $\gamma_{\mathrm{m}}$ and $\gamma_{\mathrm{c}}$ are the surface energies of the metal and ceramic, respectively, and $\gamma_{\mathrm{mc}}$ is the metalceramic interfacial energy. This indicates that the work of adhesion $W_{\text {ad }}$ increases with decreasing the metal-ceramic interface energy $\gamma_{\mathrm{mc}}$. Probably the interfacial energy for ZTA-metal couple is much less, in which a larger work of adhesion is generated if comparing to that for TZP-metal couples. A direct evidence is that a larger amount of the metal adhered on the ZTA than on the TZP. Esposito et al. [20] found that stainless steel (nominal composition: $\mathrm{Cr} 17.2 ; \mathrm{Ni}$ 8.3; Fe 71.2; Si $1.2 \mathrm{wt} . \%$ ) has a greater tendency to transfer metal to the $\mathrm{Al}_{2} \mathrm{O}_{3}$ contact face than superalloy $(\mathrm{Cr} 20.0 ; \mathrm{Ni}$ 73.5; Ti 2.5; $\mathrm{Al} 2.0 \mathrm{wt} \%$ ). A strong adhesion of $\mathrm{Fe}$ on $\mathrm{Al}_{2} \mathrm{O}_{3}$ is observed in literature [20] which indicates that the amount of metallic film transferred to the ceramic surface depends on the physical properties of metal [10]. In the present study, the metallic particles adhere less to the TZP surfaces if compared with ZTA which is presumably due to the presence of $\mathrm{Al}_{2} \mathrm{O}_{3}$. This is in agreement with the results obtained by Libsch et al.[19]. They reported that for SAE 4620 carburized steel against ceramics a thick film was formed on the ceramic wear surface of $\mathrm{Al}_{2} \mathrm{O}_{3}-\mathrm{ZrO}_{2}$ materials whereas only a very few metallic particles were transferred to the ceramic surface of $\mathrm{ZrO}_{2}-\mathrm{Y}_{2} \mathrm{O}_{3}$ materials. It can be suggested that the metal particles (specially for steel) have a strong adhesion on $\mathrm{Al}_{2} \mathrm{O}_{3}$ materials or $\mathrm{Al}_{2} \mathrm{O}_{3}$ based materials such as ZTA.

\subsection{Frictional behaviour $v s$. the adhered metallic film in the ZTA-metal couple}

For the ZTA-AISI-52100 pair the coefficient of friction $(\mu)$ reveals a significant variation with increasing sliding distance. This trend in the coefficient of friction results from the formation of a metallic film on the ceramic surface. It was found that after a few minutes a metallic film was transferred from the AISI-52100 steel plate to the ceramic surface. The metallic layer on the ZTA ceramic, however, was not yet well developed and was discontinuous. With the sliding process continuing, much more metallic particles were transferred from the steel plate to the ceramic surface, resulting in an increase of thickness and area coverage, and finally forming a thick and relatively continuous layer. Owing to variation in thickness of the transferred layer in the running-in period the coefficient of friction may vary, according to the theory described by Bowden and Tabor [25]. That is

$\mu=\frac{\tau_{\mathrm{i}}}{H}$

where $\tau_{\mathrm{i}}$ is the shear strength of the layer and $H$ is the hardness of (a) the metallic layer in the case of a thick layer or (b) the hardness of the softest contacting partners, in this case the metal, for the situation when a relative thin layer is present. This equation indicates that the coefficient of friction depends 
on the metallic layer. When the transfer layer thickness reached a certain level, the metallic film became relatively constant, i.e. the average hardness of the metallic layer kept a constant value, so a constant coefficient of friction is obtained. A thick and continuous film has been observed from the wear track of ZTA (see Fig. 5(a)). A similar observation of a variation of the coefficient of friction owing to the formation and the increase of the thickness of a transferred metallic layer on the ceramics was also pointed out by Stachowiak et al. [10].

The stable values of the coefficient of friction are in the range of 0.75-0.9 for ZTA-AISI-52100 pair, which is in good agreement with the values ( $0.75-0.85)$ obtained by Czichos et al. [21,22] for $\mathrm{Al}_{2} \mathrm{O}_{3}$-AISI-52100 pairs. Their experiments were performed with a ceramic pin by using the pinon-disk test system. The microhardness $(16.1 \mathrm{GPa})$ of their $\mathrm{Al}_{2} \mathrm{O}_{3}$ was nearly the same as for ZTA (in Table 1) used in the present experiments. Envirònmental conditions were almost the same, but normal load and surface roughness of the specimen used were different. In this study it is found that the coefficient of friction is independent of normal load in this study (Table 2) and metallic particles adhered to ceramics independence of surface roughness is found by $[10]$. Comparison of both ZTA-AISI-52100 and $\mathrm{Al}_{2} \mathrm{O}_{3}$-AISI52100 pairs indicated that the presence of a similar thick metallic film transferred from the steel to the ceramic and the same softer metal partner resulted in a similar value of coefficient of friction.

\subsection{Difference in coefficient of friction between ZTA- and TZP-metal couples}

In Fig. 2, it is shown that the coefficient of friction for ZTA-AISI-52100 pairs is nearly a factor of about 2.6 higher than the TZP-AISI-52100 pair owing to the presence of a thick metallic film. With the adhesion friction theory as given by Bowden and Tabor [25], the difference is explained as follows.

The dynamic hardness $H_{\mathrm{Di}}$ of the metallic film on the ZTA ceramic surface is $2.3 \mathrm{GPa}$. $H_{\mathrm{D}}$ of the original surface of the materials is given in Table 1. The dynamic hardness of the worn surface of both TZPs is almost the same as the original surface. It is assumed that the shear strength $\left(\tau_{\mathrm{i}}\right)$ is the same in all cases. Then the coefficient of friction found for TZPAISI-52100 couples is

$$
\mu_{\mathrm{TZP}}=\frac{\tau_{\mathrm{i}}}{H_{\mathrm{AISI}-52100}}
$$

and for ZTA-AISI-52100 couple is

$$
\mu_{\mathrm{ZTA}}=\frac{\tau_{\mathrm{i}}}{H_{\mathrm{Di}}}
$$

where $H_{\text {AISI-52100 }}$ is the hardness of AISI-52100 steel, the softest contact partner. $H_{\mathrm{Di}}$ is the hardness of the thick metallic layer.
The ratio is

$\frac{\mu_{\mathrm{ZTA}}}{\mu_{\mathrm{TZP}}}=\frac{H_{\mathrm{AISI}-52100}}{H_{\mathrm{Di}}} \approx \frac{6.3}{2.3} \approx 2.7$

This value is in agreement with the measured coefficient of friction, i.e. $\mu_{\mathrm{ZTA}} \approx 0.9, \mu_{\mathrm{TZP}} \approx 0.35$ which gives a ratio of 2.6 for the respective friction coefficients.

\subsection{Wear mechanisms in ZTA}

For ZTA ceramics, a thick and continuous metal layer is found on the overall wear track (see Fig. 5(a)) which obviously plays a protective role. This interfacial adhesion layer prevents contact of ZTA to the steel. The predominant wear takes place between the metallic layer and the steel. Grain pull-out of the ceramic may only occur, when the strength of the adhesive bonds of metal to ceramic is larger than the grain boundary strength, This is not of common occurrence in the present case.

The hardness, as defined as the resistance against plastic deformation, plays an important role on the wear values when a hard ceramic slides against a relative softer metal as expressed in Archard's theory [26]. The hardness value of ZTA ceramic $\left(H_{v}=17.0 \mathrm{GPa}\right.$ or $\left.H_{\mathrm{D}}=10.2 \mathrm{GPa}\right)$ is much higher than that of AISI-52100 hardened steel $\left(H_{\mathrm{v}}=7.6 \mathrm{GPa}\right.$ or $H_{\mathrm{D}}=6.3 \mathrm{GPa}$ ). So ZTA ceramic has a high resistance to scratching due to the steel and to plastic deformation in the contact area during sliding wear. In contrast to ZTA ceramic, there is a considerable evidence of plastic deformation in the steel surface, which leads to wear loss of the steel by plastic scratching and plastic adhesive wear. The strong effect of this hardness ratio on wear rate was also found by Zum Gahr [27]. Who revealed that the wear rate of a metallic ring increased with increasing hardness ratio, while the wear losses of the ceramic pin decreased in that case.

According to Libsch et al. [19], ceramics with high toughness can withstand higher loads without macrodamage. They found that in the fracture toughness range of 2.5-6.6 MPa $\mathrm{m}^{1 / 2}$ of ZTA ceramics, a macrodamage (chipping and cracking) occurs at loads of about $136 \mathrm{~N}$. In the present study, surface damage (chipping and cracking) did not occur in the ZTA ceramic with fracture toughness value of $5.2 \mathrm{MPa} \mathrm{m}^{1 / 2}$ at loads of $65200 \mathrm{~N}$ as observed by SEM (see Fig. 5). Only few grain pull-out by adhesive wear was found. The thick continuous and relative homogenous metallic layer can reduce local loads or stresses on the ceramic surface. The difference between the present results and those of Libsch may be due to the difference in tribological test system. They used the Falex ring on ceramic block test technique where the Falex S-25 rings are made of SAE 4620 carburized steel. For the ZTA-AISI-52100 couple, the dominant mechanism under dry sliding is adhesive wear of the metallic layer on the ceramic surface. 


\section{5. wear mechanisms in TZP}

In contrast to the ZTA-AISI-52100 couple, where wear was hardly observed at the ceramic specimens but mainly on the steel components, the wear rates of steel and ceramic are comparable for both TZP ceramics. Comparison of the wear between ZTA and both TZP ceramics indicates that the wear rates of the TZP ceramics are about a factor of 3 or 4 higher than that of ZTA. A very thin metal film adhered on TZP ceramic surfaces was observed (judging by the colour using an optical microscope) at overall area and also a few thick and small islands are present on the TZP surfaces (see Fig. 6 , black parts). These islands contain iron oxides, metallic and ceramic turnings.

The hardness ratio of the TZP pin-metallic plate is much lower than that for the ZTA-metal couple. Along Zum Gahr's line of discussion [27], one might expect that the wear rate of TZP ceramics will increase and the wear rate of the steel will decrease if compared with the ZTA-metal couple, which is in agreement with our results.

During the sliding process, a plastic deformation of the surface layer of the wear track takes place. This plastic deformation may produce subsurface cracking and may cause surface damage [19]. Very large local stresses on the ceramic surface produced by asperity contact cause surface or subsurface cracking on a very fine scale which also result in surface damage. Fig. 10(a) shows a micrograph of surface damage or microfracture along weak grain boundaries, which gives considerable evidence of intergranular fracture. In these areas, the wear debris can easily be entrapped, smeared out and pressurised to form a small thick and dense islands during sliding as seen in Fig. 10(b). These isolated thick islands can provide a protection for further microfracture, but in most cases they cause local stress concentration. If the bonding between particles of the island or between the islands and the ceramic surface is strong enough, it is assumed that these islands can cause subsurface cracking or grain pull-out under high local stresses, resulting in further surface damage. The high toughness of TZP ceramics provides a large resistance for the propagation of cracks and counteracts microfracture on a large scale. This is the reason that microfracture is limited to a small scale and no large main cracks are found in this case.

On the wear track of TZP ceramics, grooves are clearly visible in the sliding direction. This groove wear is caused by harder wear particles, which can be ceramic particles or iron oxide products. Some wear particles of TZP ceramics adhered or embedded on the steel surface (identified by EDX analysis) in combination with the iron oxide particles of the steel surface promote groove wear.

Observation and examination of the whole wear track of TZP under dry sliding show that the main wear mechanism is a combination of adhesive wear, plastic deformation and groove as well as some microfracture on small scale.

For the ceramics tested wear rates were measured less than $10^{-6} \mathrm{~mm}^{3} \mathrm{~N}^{-1} \mathrm{~m}^{-1}$ which is acceptable in practical appli-

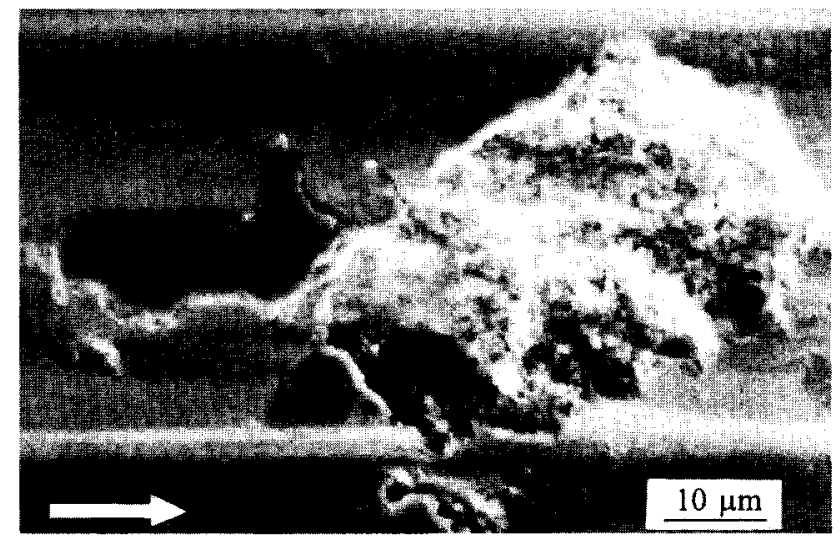

(a)

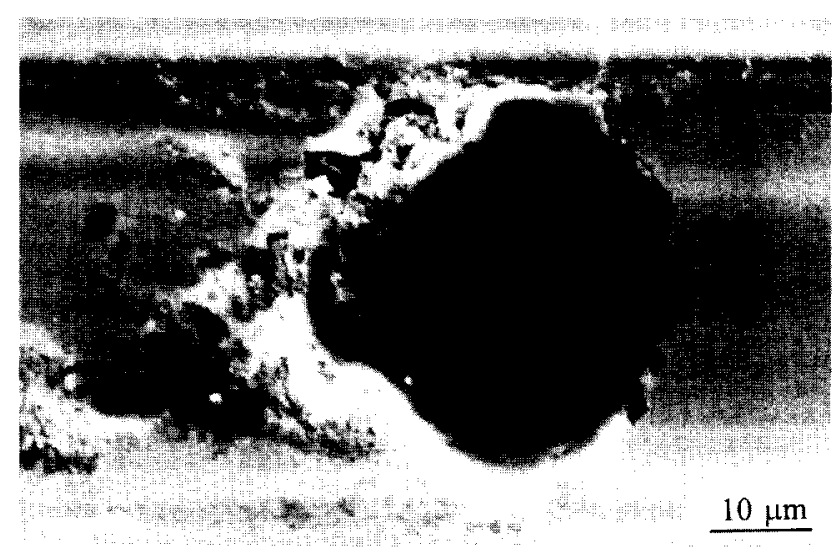

(b)

Fig. 10. Morphology of the TZP surface damage atter dry sliding: (a) microfracture; (b) isolated thick islands of the wear debris on the track.

cations. If a very high wear resistance of ceramic components is required, for example cutting tools, ZTA is a good candidate. For high wear resistance of both components in ceramic-metal couples, however, ZTA is not favourable owing to the high wear rate of the contacted metallic partner. In this case the use of TZP ceramics is favourable.

\subsection{Effect of water on the tribology of TZP ceramics}

The SEM micrograph in Fig. 11 shows no microcracks on the worn surface after wear experiments in water. SEM observation of the worn surface and EDX analysis indicate the absence of a metallic layer transformed to the TZP surface in water condition. The worn surface is smooth, even more smooth than the worn surface under dry condition. The water treated samples, however, contain small shallow pits. These pits indicate that the TZP plate is less resistant to wear damage in water, which has also been found by other researchers [28]. Recent studies have pointed out that water has a marked influence on the friction and wear behaviour of zirconia ceramics, although the results are often conflicting. In comparison with the wear behaviour in air, both increased 


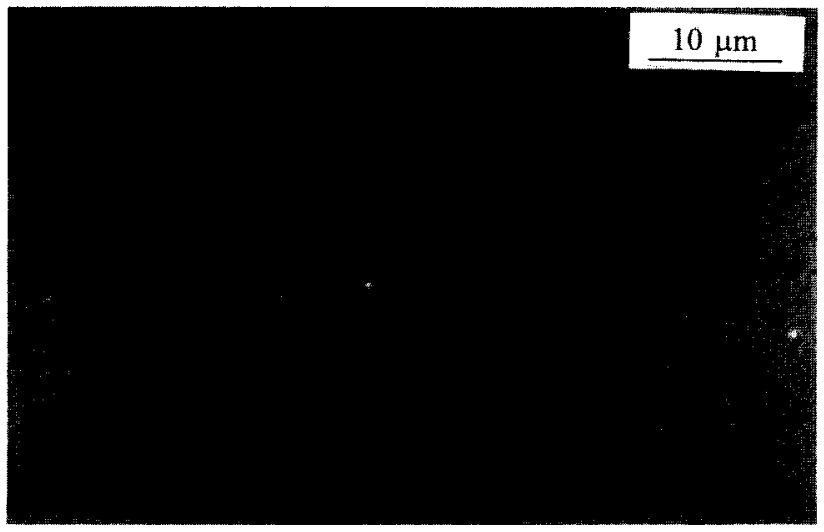

Fig. 11. SEM micrograph of the TZP wear track in water condition, smooth wear track with small shallow pits.

$[27,29,30]$ and decreased [31] wear of zirconia ceramics in water have been reported.

A wear acceleration mechanism reveals that water promotes wear by stress corrosion reaction [30-32] on the sliding surface due to the reaction of ceramic with water. It is expected that soft hydroxides are formed on the TZP surface, which result in a tribochemical wear. Tribochemical reactivity does not depend on the surrounding temperature, but the reactivity of stress corrosion cracking is accelerated with increasing the temperature [33]. Although the soft reaction products may relax the shear stress on the contact surface by plastic deformation, they can greatly reduce the mechanical strength of materials, resulting in easy removal of wear particles from the ceramic surface. Sasaki [33] mentioned that water is adsorbed on the fresh surface and reacts with zirconia, involving a chemisorption of $\mathrm{OH}^{-}$ions at the surface and breaking the $\mathrm{Zr}-\mathrm{O}-\mathrm{Zr}$ bonds. This promotes the phase transformation from tetragonal to monoclinic zirconia and generates a network of microcracks, which deteriorates the strength of the surface and thus increases wear. The influence of the phase transformation on the wear does not take place in the present study since no monoclinic phase is detected. The prevention of this phase transformation is based on the small grain size of zirconia [34]. In other literature [35] it is expected that water penetrates and interacts with microcracks at interfaces, replacing strong solid-solid interaction by weak solid-liquid-solid interaction. Finally the interface attraction or interface energy is reduced by capillary condensation, which is described in detail by Lawn [35], resulting in more wear loss of the ceramic during sliding in water.

On the other hand, the wear particles forming a colloidal suspension with water can be entrapped at the interface and promote fine scratching or fine polishing of TZP surface, which lead to accelerative wear. Another factor of acceleration of the wear in water is that the iron oxidation on the steel surface is promoted by water. Comparing with dry condition, another factor is the absence of a metallic layer on the ceramic surface.

\section{Conclusions}

(1) The test results of the friction and the wear in the present tribosystems are reproducible.

(2) In ZTA-AISI-52100 couples, a thick metallic film is transferred on the ceramic surface. In contrast, only a very thin metallic film adheres to the ceramic surface in both TZP-AISI-52100 couples. The adhesion of the metal layer on ZTA ceramics is stronger than that on TZP ceramics. The presence of soft and thick metallic layer is responsible for the high coefficient of friction of the ZTA tribological system.

(3) The coefficient of friction of the ZTA-AISI-52100 couples is a factor of 2 more than that of the TZP-AISI52100 couples. The values of the coefficient of friction depend on the shear stress and the hardness of the contacted surfaces or the hardness of the transformed metallic layer if adhesive wear occurs as the main process.

(4) Wear rates less than $10^{-6} \mathrm{~mm}^{3} \mathrm{~N}^{-1} \mathrm{~m}^{-1}$ for all tested ceramics are obtained at the following conditions: at normal load of $65 \mathrm{~N}$, sliding speed of $20 \mathrm{~mm} \mathrm{~s}^{-1}$ and unlubricated testing distance of $6.9 \mathrm{~km}$. The best wear resistance of the three ceramic materials is ZTA ceramic, i.e. $0.2-0.5 \times 10^{-7} \mathrm{~mm}^{3} \mathrm{~N}^{-1} \mathrm{~m}^{-1}$; however, the highest wear rate is generated at the metal plate, i.e. $8.3 \times 10^{-5} \mathrm{~mm}^{3} \mathrm{~N}^{-1} \mathrm{~m}^{-1}$. For the tribosystem as a whole, the TZP-metal couples are favourable if compared with the ZTA-metal couple. The variation of loads from 65 to $200 \mathrm{~N}$ does not affect the tribological properties of the ZTA-AISI-52100 system.

(5) For ZTA-AISI-52100 couple, adhesive wear based on metal transfer to the ceramic surfaces is the dominant mechanism. For TZP-AISI-52100 couple, there is a combination of adhesive wear, plastic deformation and groove as well as some microfracture on small scale.

(6) During wear tests in water, the metal plate showed strong oxidation. A slightly larger wear rate of the ceramic pin is found if compared with the results obtained in air. This phenomenon can be contributed by the following factors: (i) a softer hydroxide produced on the TZP surface due to tribochemical reaction between water and TZP ceramics, (ii) water, penetrating and chemically interacting with crack interfaces, which reduces interface energies, (iii) absence of the thick metallic layer on the ceramic surface. However, all these factors may not provide a strong influence on the wear of TZP ceramics as observed. In this study, no phase transformation from tetragonal to monoclinic form occurs on the contacted area.

\section{Acknowledgements}

The authors would like to thank Ing. Erik de Vries for his assistance of adjusting the test machine, Mr. Marc Smithers 
for ultra-thin-window EDX analysis, Jaap Boeijsma for XRD mcasurcments. This rescarch was partly supported by the Innovative Research Program on Technical Ceramics (IOPTK) with the financial aid of the Dutch Ministry of Economic Affairs.

\section{References}

[1] S. Asanabe, Applications of ceramics for tribological components, Tribol. Int., 20 (1987) 355

[2] L.D. Wedeven, R.A. Pallini and N.C. Miller, Tribological examination of unlubricated and graphite-lubricated silicon nitride under traction stress, Wear, 122 (1988) 183-205.

[3] R.C. Garvie, R.H.J. Hannink and R.T. Pascoe, Ceramic steel?, Nature (London), 258 (1975) 703-704.

[4] P. den Exter, Synthesis, microstructure and mechanical properties of zirconia-alumina composites, Ph.D. Thesis, University of Twente, 1991.

[5] Y.J. He, A.J.A. Winnubst, H. Verweij and A.J. Burggraaf, Improvement of Mechanical properties of zirconia toughened alumina by sinter forging, to be published in J.Mater. Sci.

[6] N. Narutaki, Y. Yamane, K. Hayashi and T. Hoshi, Cutting performance and wear characteristics of an alumina-zirconia ceramic tool in high speed face milling, Ann CIRP, 40 (1) (1991) 49-52.

[7] T. Somakumar, R. Krishnamurthy and C.V. Gokularathnam, Machining performance of phase transformation toughened alumina and partially stabilised zirconia composite cutting tools, J. Eur. Ceram. Soc., 12 (1993) 455-460.

[8] J. Wang and R. Stevens, Review: zirconia-toughened alumina (ZTA) ceramics, J. Mater. Sci., 24 (1989) 3421-3440.

[9] V. Aronow and T. Mesyet, Wear in ceramic/ceramic and ceramic/ metal reciprocating sliding contact. Part 1, J.Tribol., 108 (1986) 1621.

[10] G.W. Stachowiak, G.B. Stachowiak and A.W. Batchelor, Metallic film transfer during metal-ceramic unlubricated sliding, Wear, 132 (1989) 361-381.

[11] D.H. Buckley and K. Miyoshi, Friction and wear of ceramics, Wear, 100 (1984) 333-353.

[12] W. Groot Zevert, A.J.A. Winnubst, G.S.A.M. Theunissen and A.J. Burggraaf, Powder preparation and compaction behaviour of fine-grain Y-TZP, J. Mater. Sci., 25 (1990) 3449.

[13] M.I. Mendelson, Average grain size in polycrystalline ceramics, J.Am. Ceram. Soc., 52 (8) (1969) 443-446.

[14] F.J. Esper, K.H. Friese and H. Geier, Mechanical, thermal, and electrical properties in the system of stabilized $\mathrm{ZrO}_{2}\left(\mathrm{Y}_{2} \mathrm{O}_{3}\right) / \alpha-\mathrm{Al}_{2} \mathrm{O}_{3}$, Adv. Ceram., 24B (1988) 528-532.

[15] ASM International Handbook Committee, Properties and selections of iron, steels and high performance alloys, Metals Handbook, Vol. 1, 10th edn., ASM International, 1990.

[16] W.D. Nix, Mechanical properties of thin films, Metall. Trans. A, 20, (1989) 2217-2242.
[17] R. Hofman, The protection of alloys against high temperature corrosion by $\mathrm{SiO}_{2}$ coatings, Ph.D. Thesis, University of Twente. The Netherlands, 1993.

[18] D. Bialo, J. Duszczyk, A.W. J de Gee, G.J.J. van Heijningen and B.M. Korevaar, Friction and wear behaviour of cast and sintered Al-Si alloys under conditions of oscillating contact, Wear, 141 (1991) 291-309.

[19] T.A. Libsch, P.C. Becker and S.K. Rhee, Dry friction and wear of toughened zirconias and toughened aluminas against steel, Wear, 110 (1986) 263-283

[20] L. Esposito and A. Tucci, Tribological behaviour of ceramic/ceramic and metal/ceramic couples, in P. Durán and J.F. Fernández (eds.), Proc. 3rd Euro-ceramics Conf., Vol.3, 1993, pp. 301-306.

[21] H. Czichos, S. Becker and J. Lexow, Mulilaboratory tribotesting: Results from the versailles advanced materials and standards programme on wear test methods, Wear, 114 (1987) 109-130.

[22] H. Czichos, S. Becker and J. Lexow, International multilaboratory sliding wear tests with ceramics and steel, Wear, 135 (1989) 171191.

[23] A. Ravikiran and B.N. Pramila Bai, Water-lubricated sliding of $\mathrm{Al}_{2} \mathrm{O}_{3}$ against steel, Wear, 171 (1993) 33-39.

[24] J.M. Howe, Bonding, structure, and properties of metal/ceramic interfaces: Part 1 chemical bonding, chemical reaction, and interfacial structure, Int. Mater. Rev., 38 (5) (1993) 233-256.

[25] F.P. Bowden and D. Tabor, The Friction and Lubrication of Solids, Oxford University Press, 1950.

[26] (a) J.F. Archard, Contact of rubbing surfaces, J. Appl. Phys., 14 (8), (1953) 981-88. (b) J.F. Archard and W. Hirst, The wear of metals under unlubricated conditions, Proc. R. Soc. London, Ser. A, 236 (1206) (1956) 397-410.

[27] K.-H. Zum Gahr, Sliding wear of ceramic-ceramic, ceramic-steel and steel-steel pairs in lubricated and unlubricated contact, Wear, 133 (1989) 1-22

[28] G.W. Stachowiak, G.B. Stachowiak, Environment effects on wear and friction of toughened zirconia ceramics, Wear, 160 (1993) 153-162.

[29] R.H.J. Hannink, J.J. Murray and H.G. Scott, Friction and wear of partially stabilized zirconia: basic science and practical applications, Wear, 100 (1984) 355-366.

[30] T.E. Fischer, M.P. Anderson, S. Jahanmir and R. Salher, Friction and wear of tough and brittle zirconia in nitrogen, air, water, hexadecane and hexadecane containing stearic acid, Wear, 124 (1988) 133-148.

[31] S. Sasaki, The effects of the surrounding atmosphere on the friction and wear of alumina, zirconia, silicon carbide and silicon nitride, Wear, 134 (1989) 185-200.

[32] J. Ishigaki, R. Nagata and M. Iwasa, Friction and wear of partially stabilized zirconia, Proc. 50 Years of Tribology Conf., July 1-3, 1987 , pp. 609-614.

[33] S. Sasaki, Effects of environment on friction and wear of ceramics, Bulletin of Mechanical Engineering Laboratory, Japan, ISSN 03742725, 1992.

[34] A.J.A. Winnubst and A.J. Burggraaf, The ageing behaviour of ultrafine grained Y-TZP, Adv. Ceram., 24A (1989) 39-48.

[35] B. Lawn, Friction processes in brittle fracture, in I.L. Singer and H.M. Pollock (eds.), Fundamentals of Friction: Macroscopic and Microscopic Processes, NATO ASI Series, 1992, pp. 137-165. 